\title{
Lactational Changes Masquerading Features of Malignancy in Breast: A Case Report
}

\author{
Lakshmi Agarwal, Manmohan Agrawala and Bhawna Gupta \\ Department of pathology, Government medical college, Kota, India \\ Pushpadi cancer care centre, Kota, India
}

\begin{abstract}
Introduction: Pregnancy associated breast cancer is defined as "The diagnosis of breast cancer is made during pregnancy or within one year afterward." The incidences of breast carcinoma are 1 in 3000 pregnancy in west. Risk is increasing because of increased number of late pregnancies. Young age, lactating breast (dense) and paucity of incidences not only delay but confuse the pathologist for accurate diagnosis.

Case Report: A 28 year lactating female with 2 months old baby, presented with breast lump. Lump was mobile, non-tender and of size $2 \times 1 \mathrm{~cm}$ since 3 months and gradually increasing in size. On USG, it was benign. On FNAC, aspirate was milky mixed with blood, showing monotonous cells with abundant cytoplasm, bland nuclei in a secretary background. Final diagnosis was lactational changes in breast. After six months, lady came back with previous lump which was increased in size up to $6 \mathrm{X} 5 \mathrm{~cm}$. On FNAC, smear was having bizarre cells, reported as malignant and confirmed on histopathology. Patient was responded to chemotherapy and lump reduced in size.
\end{abstract}

Conclusion: Pregnancy associated breast cancer is on rise. High grade of suspicion and complete evaluation including trucut biopsy will lead to correct diagnosis.

Keywords: Lactation, Young Age, Breast Carcinoma

\section{Introduction}

Pregnancy associated breast cancer is defined as "The diagnosis of breast cancer is made during pregnancy or within one year afterward." Risk is increasing because of increased number of late pregnancies. ${ }^{1}$ Young age, lactating breast (dense) and paucity of incidences not only delay but confuse the pathologist for accurate diagnosis. Moreover, cytologically lactating adenoma mimics infiltrating duct carcinoma.The diagnostic and therapeutic implications in this clinical setting are special as physicians have to balance between aggressive maternal care and fetal protection.

\section{Case Report}

A 28 year old lactating female with 2 months of old baby, presented in the surgical OPD with complaints of breast lump since 3 months. Lump was mobile, non-tender and of size $2 \mathrm{X} 1 \mathrm{~cm}$ and was gradually increasing in size. On USG, it was benign. FNAC was performed using the 24 gauge needle attached with $10 \mathrm{ml}$ syringe. Multiple smears were made. They were air dried and fixed in methanol. Smears were stained with May Grunnwald Giemsa stain. Aspirate was milky, mixed with blood in nature. Smear revealed epithelial cells arranged in clusters and singly scattered with abundant cytoplasm in a secretory dirty background. Numerous naked cells were also seen. The nuclei are enlarged with prominent nucleoli but regular nuclear contours and bland chromatin. A scarce number of bipolar naked nuclei can also be found in these smears.
Final diagnosis of lactational nodule was rendered on aspiration cytology. However Trucut biopsy was advised for confirmation and to rule out any underlying malignancy, but lost to follow up. After six months, she came back with previous lump which was increased in size up to 6 X5 $\mathrm{cm}$. FNAC was repeated. Smears showed singly scattered epithelial cells having pleomorphic hyperchromatic nuclei, irregular contour and moderate cytoplasm. Bipolar nuclei were not evident. On the basis of cell morphology, it was reported as breast carcinoma. Trucut biopsy was done and the diagnosis was confirmed Patient was referred to oncology department for further treatment and management.

\section{Discussion}

Gestational breast cancer is second most common pregnancy associated malignancies, after cervical cancer. This incidence is increasing due to delay in childbearing until later in life. Various studies have shown that women who have their term pregnancy after the age of 30 years have a two to three times higher risk of developing breast carcinoma than women who have their first pregnancy before the age of 20 years. ${ }^{2}$

Histopathologic and immunohistochemical features of lactational breast carcinoma are similar to those of nonpregnant women with breast cancer. Anderson et al ${ }^{3}$ and Ishida et $\mathrm{al}^{4}$ documented no difference in the prognosis 
of early cancers (when matched for age and stage), but a poorer prognosis is demonstrated for patients with more advanced disease. Moreover estrogen and progesterone receptor status negativity is consistently greater in these patients. This is due to the fact that high circulating levels ofestrogen and progesterone in pregnancy occupy all of the hormone receptor binding sites and receptor are downregulated. ${ }^{5,6,7}$ Unfortunately most of the patients present with advanced disease. This is due to lack of awareness and difficulty in diagnosis. Physiologic changes during pregnancy changes the architecture of the breast. The breast enlarges due to proliferation of ducts and lobules which alter the breast structure, resulting in enlargement, firmness, and increased nodularity. This may also result in diagnostic delay in diagnosis. Lactational changes masquerade the features of malignancy. Lactating adenoma are most prevalent breast masses in pregnancy. ${ }^{8}$ In the present case the first diagnosis was rendered lactational adenoma due to bland nature of chromatin and uniform nuclear contour. But it turned out to be malignant after six month. Therefore this case highlights three possibilities:

- Coexisting malignancy with lactational adenoma

- Lactational adenoma developed into IDC

- Diagnostic dilemma

There are case reports of patients who develop invasive ductal carcinoma in previous excision site of a lactating adenoma and lactating adenoma containing an associated infiltrating carcinoma.Geschicker ${ }^{9}$ and Lewis reported a lactating adenoma containing an associated infiltrating carcinoma. Hertelet al. ${ }^{10}$ reported a case report of lactational adenoma developed into IDC.

Awareness of entity is important as pregnancy associated breast cancerbehaves aggressively, present in late stage but can be cured with appropriate treatment at proper time. Early diagnosis can prevent the morbidity and mortality of the patient. FNAC can result in false positive and negative cases due to pregnancy associated hyperplastic changes atypia. So tissue biopsy and close follow up of the patient is required to diagnose pregnancy associated breast lump.
High grade of suspicion and complete evaluation including trucut biopsy will lead to correct diagnosis.

\section{Conclusion}

All cases of pregnancy associated breast lumps showing lactational changes $\&$ high cellularity on cytosmears should be kept in close follow-up. A tru-cut biopsy should be done to confirm the absence of malignancy. Since tru-cut biopsy is not done routinely in our setup, diagnosis \& management of patient was delayed. A multidisciplinary approach and close coordination between medical oncology, surgical oncology and obstetricians is recommended.

\section{References}

1. Anderson JM. Mammary cancers and pregnancy. Br Med J 1979;1:1124-7.

2. Middleton L, Amin M, Gwyn K, et al. Breast carcinoma in pregnant women-assessment of clinicopathologic and immunohistochemical features. Cancer 2003;98(5):105560.

3. Anderson BO, Petrek JA, Byrd D, et al. Pregnancy influences breast cancer stage at diagnosisin women 30 years of age and younger. Ann SurgOncol 1996;3(2):204-11.

4. Ishida T, Yokoe T, Kasumi F, et al. Clinicopathologic characteristics and prognosis of breastcancer patients associated with pregnancy and lactation: analysis of casecontrol study inJapan. Jpn J Cancer Res 1992;83:1143-9.

5. Woo JC, Taechin Y, Hurd T. Breast cancer in pregnancy- a literature review. Arch Surg 2003;138:91-9.

6. Antonelli NM, Dotters DJ, Katz VL, Kuller JA. Cancer in pregnancy: A review of the literature- Part I. ObstetGynecolSurv 1996;51:125-34

7. Bonnier P, Romain S, Dilhuydy JM, et al. Influence of pregnancy on the outcome of breastcancer: a case-control study. Int J Cancer 1997;72:720-7.

8. Baker TP, Lenert JT, Parker J, et al. Lactating adenoma: a diagnosis of exclusion. Breast J 2001;7:354-7.

9. Cheek JH. Cancer of the breast in pregnancy and lactation. Am J Surg 1973;126:729-31.

10. Geschicker CF, Lewis D. Pregnancy and lactation changes in fibro-adenoma of the breast. BMJ 1938;1:499-503.

*Corresponding author:

Dr Lakshmi Agarwal, Department of pathology, Government medical college, Kota, India

Phone: +91

Email: drlaxmiagarwal@gmail.com

Date of Submission : 07.12.2017

Date of Acceptance : 12.12.2017

Financial or other Competing Interests: None.

Date of Publication : 15.12.2017

http://www.pacificejournals.com/awch 